\title{
Obesity and overall mortality: findings from the Jackson Heart Study
}

\author{
Yuan-I Min * D, Yan Gao, Pramod Anugu, Anshul Anugu and Adolfo Correa
}

\begin{abstract}
Background: Overall mortality has been reported to be lower among individuals classified as overweight/obese when compared with their normal weight counterparts ("obesity paradox") when obesity classification is based on the body mass index (BMI). One possible reason for this apparent paradox is that BMI is not a reliable measure of obesity-related risk as it does not differentiate fat mass from lean muscle mass or fat mass phenotypes. Waist circumference (WC), as a measure of central adiposity, may be a better indicator of obesity-related risk. We examined the association of overall mortality with BMI and with WC measures, including WC, waist-to-height ratio (WHtR) and waist-to-hip ratio (WHR).

Methods: Data from 3976 African American participants (551 deaths) in the Jackson Heart Study (JHS) were analyzed. Cox regression models were used to perform survival analysis. Obesity measures were analyzed as dichotomous (obese/non-obese) and continuous variables. Baseline covariates included age, sex and smoking status.
\end{abstract}

Results: Comparing obese to non-obese participants, adjusted hazard ratios $(95 \% \mathrm{Cl})$ for overall mortality were 1.14 $(0.96,1.35), 1.30(1.07,1.59), 1.02(0.73,1.41)$ and $1.45(1.18,1.79)$ when using BMI, WC, WHtR and WHR, respectively. For BMI, WC and WHtR, a J-shaped relationship was observed with overall mortality. For WHR, a monotonic increasing relationship was observed with overall mortality.

Conclusions: In the JHS, we found that obesity as defined by WC and WHR was associated with an increased risk of overall and CVD mortality, while obesity defined by BMI was associated only with an increased risk of CVD mortality. WHR was the only obesity measure that showed a monotonic increasing relationship with overall and CVD mortality.

Keywords: Obesity, Body mass index, Waist circumference, Waist-to-height ratio, Waist-to-hip ratio, Mortality, Overall mortality, Cardiovascular mortality, Cancer mortality

\section{Background}

Overall mortality has been reported to be lower among individuals classified as overweight/obese based on body mass index (BMI, $\mathrm{kg} / \mathrm{m}^{2}$ ) when compared with their normal weight counterparts ("obesity paradox") both in the general population and in population subgroups [1-5]. In a systematic review of prospective studies of obesity and

\footnotetext{
*Correspondence: ymin@umc.edu

The Jackson Heart Study, University of Mississippi Medical Center, 350 W. Woodrow Wilson Avenue, Ste. 701, Jackson, MS 39213, USA
}

mortality among general populations of adults using normal weight (BMI 18.5 to $<25$ ) as a reference group, overweight (BMI 25 to $<30$ ) was associated with a significantly lower overall mortality, grade 1 obesity (BMI 30 to < 35) was not associated with a higher overall mortality, and grades 2 and 3 obesity $(\mathrm{BMI} \geq 35)$ were associated with a significantly higher overall mortality [1]. Similar findings have been reported in the elderly population and among patients with chronic kidney disease, coronary heart disease, heart failure and chronic obstructive pulmonary disease [2-5].

C The Author(s). 2021 Open Access This article is licensed under a Creative Commons Attribution 4.0 International License, which permits use, sharing, adaptation, distribution and reproduction in any medium or format, as long as you give appropriate credit to the original author(s) and the source, provide a link to the Creative Commons licence, and indicate if changes were made. The images or other third party material in this article are included in the article's Creative Commons licence, unless indicated otherwise in a credit line to the material. If material is not included in the article's Creative Commons licence and your intended use is not permitted by statutory regulation or exceeds the permitted use, you will need to obtain permission directly from the copyright holder. To view a copy of this licence, visit http://creativecommons.org/licenses/by/4.0/. The Creative Commons Public Domain Dedication waiver (http://creativecommons.org/publicdomain/zero/1.0/) applies to the data made available in this article, unless otherwise stated in a credit line to the data. 
The J-shaped relationship between BMI and overall mortality is perplexing and cannot be completely explained by potential selection biases, such as survival bias and healthy participant effect [6]. One plausible reason is that BMI does not differentiate the weight of fat mass from the weight of lean body mass or fat mass distribution phenotypes across the BMI continuum and as such is not a reliable measure of the risk of obesityrelated disease. In a prospective cohort study of US male health professionals, a strong positive monotonic association was observed between predicted fat mass and overall mortality and a U-shaped association between predicted lean body mass and overall mortality, suggesting the "obesity paradox" may be largely attributable to low lean body mass, rather than low fat mass, in the lower BMI range [7]. Similarly, in a population-based cohort study of older men in UK [8], both sarcopenia and central adiposity were found to be associated with greater overall mortality, with the highest risk found in sarcopenic obese men.

Waist circumference (WC) is the most common and simplest way to measure central adiposity, which is a major contributor to disease and death. Among African Americans who are known to have relatively less of their body mass in their trunks and relatively more in their extremities compared to non-Hispanic white, WC measures of obesity may offer a more reliable assessment of obesity and mortality relationships [9]. In this study, we compared the associations of overall mortality with BMI and with other obesity measures, including WC, waist-to-height ratio (WHtR) and waist-to-hip ratio (WHR) in the Jackson Heart Study (JHS), a population-based African American cohort in the US. We hypothesized that obesity measures that incorporate waist circumference, a better measure of central adiposity and risk of obesityrelated disease than $\mathrm{BMI}$, will show a more consistent pattern of increasing risk of overall mortality with increasing level of obesity. In addition, we also evaluated the associations of these obesity measures with two leading causes of mortality, CVD and cancer, given the strong correlations between measures of obesity and cardiometabolic risk factors as well as risks of some cancers [10-12].

\section{Methods}

\section{Data source}

The design and data collection of the JHS has been previously described [13, 14]. Between September 2000 and March 2004, 5306 African Americans, ages 20 to 95 years, living in the Jackson, Mississippi metropolitan area were enrolled. Three clinical examinations were conducted between 2000 and 2013 (Exam 1 (baseline): 2000-2004; Exam 2: 2005-2008; and Exam 3: 2009-
2013). Surveillance of CVD events and deaths is still ongoing.

BMI, WHtR and WHR were calculated from weight, height, waist circumference and hip circumference measurements collected during clinical exams. Weight was measured to the nearest $0.1 \mathrm{~kg}$ and height to the nearest centimeter in light clothing and in stocking feet; waist circumference was measured to the nearest centimeter at the umbilicus; hip circumference $(\mathrm{HC})$ was measured to the nearest centimeter at the maximal protrusion. BMI was calculated as weight in kilograms divided by height in meters squared $\left(\mathrm{kg} / \mathrm{m}^{2}\right)$ [15]. WHtR was calculated as waist circumference divided by height. WHR was calculated as waist circumference divided by hip circumference.

Vital status of participants was ascertained through annual follow-up interviews, death records from the Mississippi State Health Department, obituaries and the National Death Index. Cause of death was assigned by applying algorithms developed by the National Center for Health Statistics (NCHS) using death certificates in accordance with the International Statistical Classification of Diseases and Related Health Problems, Tenth Revision (ICD-10) [16] and was provided by the Mississippi State Health Department. For out-of-state deaths, causes of death were based on ICD codes for the underlying cause of death recorded on death certificates or entered in the National Death Index. Causes of death were grouped according to the list of "rankable" causes of death used by the NCHS for reporting leading causes of death in the US [17].

\section{Analytic sample}

Because hip circumference measurements were collected at Exam 2 but not at Exam 1, anthropometric data collected at Exam 2 were used for the purpose of this analysis so that the performance of all obesity measures could be compared on the same set of participants. Participants who did not return for Exam $2(n=1101)$, with $\mathrm{BMI}<18.5 \mathrm{~kg} / \mathrm{m}^{2} \quad(n=24)$, with missing data on any of the obesity measures $(n=142)$ or smoking status $(n=63)$ were excluded. There were 3976 participants in the analytic sample. All deaths occurring through December 31, 2016 (administrative censoring date) were included in the analysis.

\section{Statistical analysis}

Survival functions by obesity status (obese/non-obese) were estimated using the Kaplan-Meier estimator and compared using the log-rank test. "Time 0" for the survival analyses was the date of Exam 2 and the administrative censoring date was December 31, 2016. The median length of follow-up was 9.2 (range: 0.01-11.2) years. Deaths due to CVD included cause of death with 
ICD-10 codes I00-I78 and deaths due to cancer included cause of death with ICD-10 codes C00-C97. Obesity status (obese/non-obese) was classified based on cut-points recommended by guidelines or reported in the literature for each obesity measure as follows: $\mathrm{BMI} \geq 30 \mathrm{~kg} / \mathrm{m}^{2}$; WC $>88 \mathrm{~cm}$ for women or $>102 \mathrm{~cm}$ for men; WHtR $\geq 0.5$; WHR $\geq 0.85$ for women or $\geq 0.9$ for men [18-20].

Obesity measures were analyzed as dichotomous variables (obese/non-obese) as well as continuous variables using restricted cubic spline with 4 knots to evaluate the non-linear relationship with mortality. The knots were placed at 5th, 35th, 65th and 95th percentiles as suggested by Harrell [21]. A model with waist and hip circumferences as separate variables was also evaluated. Statistical significance of non-linearity was evaluated using log likelihood ratio test (LRT) comparing restrictive cubic spline and linear models.

Cox regression models were performed for both unadjusted analyses and analyses adjusted for age, sex and smoking status (baseline covariates). For analyses of CVD and cancer mortalities, deaths due to other causes were treated as a competing risk and were analyzed using methods proposed by Fine and Gray [22]. Age was analyzed as a continuous variable. Smoking status was classified as current/non-current smokers. Possible effect modifications by age, sex and smoking status were tested by adding three second-order interaction terms in the models. A two-sided $p$-value $<0.05$ was considered statistically significant for all analyses. Sensitivity analysis excluding "early deaths," defined as participants who died within one year of enrollment, was performed to exclude participants who may have had a low BMI due to wasting.

\section{Results}

\section{Description of analytic sample}

The mean age of the analytic sample $(n=3976)$ was 59.8 years, $64.5 \%$ were women and $12.4 \%$ were current smokers. The prevalence of obesity was high but varied widely depending on which measure was used to classify obesity, ranging from $55.5 \%(n=2205)$ per BMI, $65.0 \%$ $(n=2585)$ per WHR, $68.4 \%(n=2719)$ per $\mathrm{WC}$, to $91.1 \%$ $(n=3622)$ per WHtR. The descriptive statistics of anthropometric measures of the analytic sample, overall and by subgroups, are shown in Table 1 .

\section{Demographic characteristics by obesity status}

For obesity per BMI, compared to non-obese participants, obese participants were younger $(<60$ years: $53.8 \%$ vs. $45.7 \%)$, more likely to be women $(70.8 \%$ vs. $56.6 \%)$ and less likely to be current smokers $(10.5 \%$ vs. $14.8 \%)$ (Table 2). In contrast, for obesity per WC, WHtR and WHR, obese participants were older than non-obese participants. In addition, for obesity per WHR, obese participants were more likely to be men and current smokers than non-obese participants.

\section{Overall mortality \\ Obesity measures as dichotomous variables (obese/non- obese)}

There were a total of 551 deaths in the analytic sample. The overall mortality rate was 15.4 per 1000 personyears. The Kaplan-Meier plots of overall mortality by obesity status (obese/non-obese) are shown in Fig. 1(a) to (d). In the unadjusted analysis, obese participants had significantly lower overall mortality compared to non-

Table 1 Descriptive statistics of anthropometric measures of the analytic sample, Exam 2 (2005-2008)

\begin{tabular}{|c|c|c|c|c|c|c|c|c|}
\hline & N (\%) & $\begin{array}{l}\text { Weight (kg) } \\
\text { Mean (SD) }\end{array}$ & $\begin{array}{l}\text { Height (cm) } \\
\text { Mean (SD) }\end{array}$ & $\begin{array}{l}\text { WC (cm) } \\
\text { Mean (SD) }\end{array}$ & $\begin{array}{l}\text { HC (cm) } \\
\text { Mean (SD) }\end{array}$ & $\begin{array}{l}\text { BMI }\left(\mathrm{kg} / \mathrm{m}^{2}\right) \\
\text { Mean (SD) }\end{array}$ & $\begin{array}{l}\text { WHtR } \\
\text { Mean (SD) }\end{array}$ & $\begin{array}{l}\text { WHR } \\
\text { Mean (SD) }\end{array}$ \\
\hline Overall & $3976(100)$ & $91.2(21.1)$ & $168.6(9.5)$ & $102.2(15.7)$ & $114.3(14.5)$ & $32.1(7.1)$ & $0.61(0.10)$ & $0.89(0.08)$ \\
\hline \multicolumn{9}{|l|}{ Age, years } \\
\hline $20-39$ & $183(4.6)$ & $99.9(29.4)$ & $171.0(10.0)$ & $102.5(20.6)$ & 117.5 (17.6) & $34.2(9.8)$ & $0.60(0.12)$ & $0.87(0.08)$ \\
\hline $40-59$ & 1814 (45.6) & $94.4(22.0)$ & $169.7(9.4)$ & $102.1(16.2)$ & $115.5(15.0)$ & $32.8(7.4)$ & $0.60(0.10)$ & $0.88(0.08)$ \\
\hline$\geq 60$ & 1979 (49.8) & $87.3(18.3)$ & $167.3(9.3)$ & $102.4(14.7)$ & 112.9 (13.5) & $31.2(6.3)$ & $0.61(0.09)$ & $0.91(0.07)$ \\
\hline \multicolumn{9}{|l|}{ Sex } \\
\hline Women & $2564(64.5)$ & $88.5(20.7)$ & $163.6(6.6)$ & $101.5(16.1)$ & 116.6 (15.2) & $33.0(7.4)$ & $0.62(0.10)$ & $0.87(0.07)$ \\
\hline Men & $1412(35.5)$ & $95.9(20.8)$ & $177.6(6.9)$ & $103.6(14.7)$ & 110.1 (12.0) & $30.3(6.0)$ & $0.58(0.08)$ & $0.94(0.06)$ \\
\hline \multicolumn{9}{|l|}{ Smoking Status } \\
\hline Current smoker & $493(12.4)$ & $88.5(20.4)$ & $170.6(9.4)$ & $100.7(14.3)$ & $110.4(13.2)$ & $30.4(6.6)$ & $0.59(0.09)$ & $0.91(0.07)$ \\
\hline Non-current smoker & $2483(87.6)$ & $91.5(21.1)$ & $168.3(9.5)$ & $102.5(15.9)$ & $114.9(14.6)$ & $32.3(7.1)$ & $0.61(0.10)$ & $0.89(0.08)$ \\
\hline \multicolumn{9}{|l|}{ BMI $\left(\mathrm{kg} / \mathrm{m}^{2}\right)$} \\
\hline$<30$ & $1771(44.5)$ & $76.1(11.1)$ & $169.7(9.5)$ & $91.1(9.0)$ & $103.5(6.7)$ & $26.3(2.5)$ & $0.54(0.05)$ & $0.88(0.07)$ \\
\hline$\geq 30$ & 2205 (55.5) & $103.2(19.3)$ & $167.7(9.3)$ & $111.2(14.1)$ & $123.0(13.2)$ & $36.7(6.1)$ & $0.66(0.08)$ & $0.91(0.08)$ \\
\hline
\end{tabular}

$S D$ standard deviation, $B M I$ body mass index, WC waist circumference, $H C$ hip circumference, WHtR waist-to-height ratio, WHR waist-to-hip ratio 
Table 2 Demographic characteristics of Jackson Heart Study Participants by obesity status, Exam 2 (2005-2008)

\begin{tabular}{|c|c|c|c|c|c|c|c|c|}
\hline & \multicolumn{2}{|l|}{ BMI } & \multicolumn{2}{|l|}{ WC } & \multicolumn{2}{|l|}{ WHtR } & \multicolumn{2}{|l|}{ WHR } \\
\hline & $\begin{array}{l}\text { Non-obese } \\
N=1771 \\
\%\end{array}$ & $\begin{array}{l}\text { Obese } \\
\mathrm{N}=2205 \\
\%\end{array}$ & $\begin{array}{l}\text { Non-obese } \\
N=1257 \\
\%\end{array}$ & $\begin{array}{l}\text { Obese } \\
\mathrm{N}=2719 \\
\%\end{array}$ & $\begin{array}{l}\text { Non-obese } \\
N=354 \\
\%\end{array}$ & $\begin{array}{l}\text { Obese } \\
\mathrm{N}=3622 \\
\%\end{array}$ & $\begin{array}{l}\text { Non-obese } \\
N=1391 \\
\%\end{array}$ & $\begin{array}{l}\text { Obese } \\
\mathrm{N}=2585 \\
\%\end{array}$ \\
\hline \multicolumn{9}{|l|}{ Age, years } \\
\hline Mean (SD) & $61.2(12.6)$ & $58.6(11.8)$ & $58.7(12.8)$ & $60.3(11.9)$ & $55.3(12.8)$ & $60.2(12.1)$ & $56.4(12.2)$ & $61.6(11.8$ \\
\hline $20-39$ & 4.0 & 5.1 & 5.7 & 4.1 & 9.0 & 4.2 & 6.8 & 3.4 \\
\hline $40-59$ & 41.7 & 48.8 & 47.8 & 44.6 & 55.4 & 44.7 & 55.5 & 40.3 \\
\hline$\geq 60$ & 54.3 & 46.2 & 46.5 & 51.3 & 35.6 & 51.2 & 37.7 & 56.3 \\
\hline \multicolumn{9}{|l|}{ Sex } \\
\hline Women & 56.6 & 70.8 & 40.6 & 75.5 & 55.1 & 65.4 & 75.3 & 58.7 \\
\hline Men & 43.4 & 29.2 & 59.4 & 24.5 & 44.9 & 34.6 & 24.7 & 41.3 \\
\hline \multicolumn{9}{|l|}{ Smoking Status } \\
\hline Current smoker & 14.8 & 10.5 & 14.2 & 11.6 & 17.5 & 11.9 & 9.8 & 13.8 \\
\hline Non-current smoker & 85.2 & 89.5 & 85.8 & 88.4 & 82.5 & 88.1 & 90.2 & 86.2 \\
\hline
\end{tabular}

$B M I$ body mass index, WC waist circumference, WHtR waist-to-height ratio, WHR waist-to-hip ratio

obese participants per the definition by BMI (hazard ratio (HR) 0.83 (95\% CI 0.70, 0.98)) (Table 3). After adjusting for age, sex and smoking status, the adjusted HRs for overall mortality were 1.14 (95\% CI $0.96,1.35)$, 1.30 (95\% CI 1.07, 1.59), 1.02 (95\% CI $0.73,1.41)$ and 1.45 (95\% CI 1.18, 1.79) comparing obese to non-obese participants per definitions by BMI, WC, WHtR and WHR, respectively (Table 3, Fig. 3).

\section{Obesity measures as continuous variables}

When obesity measures were analyzed as continuous variables using restrictive cubic spline, we observed, for overall mortality, a J-shaped relationship with BMI, WC and WHtR (Fig. 2(a) to (c)) and a monotonic increasing relationship with WHR (Fig. 2(d)) after adjusting for age, sex and smoking status. The improvement in model fit comparing the restricted cubic spline and linear models for WHR was not statistically significant (LRT, $p=0.90$ ). In the model with waist and hip circumferences as separate variables, we observed a monotonic increase in overall mortality with increasing WC after adjusting for hip circumference and a clear decreasing trend in overall mortality with increasing hip circumference up to 120 $\mathrm{cm}$ after adjusting for WC. The model fit with WC (linear) and hip circumference (cubic splines) as separate variables was better than with waist-hip-ratio (linear) as a single variable (LRT, $p<0.001)$.

\section{Effect modifications by age, sex and smoking status}

No statistically significant interactions were found between age, sex or smoking status and obesity on mortality risk whether obesity measures were analyzed as dichotomous or continuous variables (LRT, $p>0.05$ ).

\section{The effect of having multiple determinants of obesity}

We performed additional analysis to explore the effect of having multiple determinants of obesity on overall mortality. Only BMI, WC and WHR were included in this analysis because WHtR classified over $90 \%$ of participants as obese in our sample and was not associated with overall mortality. As shown in Table 4, the larger the number of determinants present, the greater the mortality risk. The adjusted HRs for overall mortality were 1.19 (95\% CI 0.86, 1.65), 1.22 (95\% CI 0.90, 1.67) and 1.54 (95\% CI 1.16, 2.06) for having 1,2 and 3 determinants, respectively. To address whether the combination of determinants matters, we further evaluated all combinations of 2 determinants of obesity and the relative mortality risks. As shown in Table 5, only the combinations that included WHR showed overall significant associations with mortality (Type 3 Test $p$-value $<0.05$ ) (scenarios b and c). The adjusted HRs were 1.50 (95\% CI $1.15,1.97)$ and 1.54 (95\% CI 1.17, 2.04) for combinations of BMI obese + WHR obese and WC obese + WHR obese, respectively.

\section{CVD and cancer mortalities}

There were 210 CVD deaths and 143 cancer deaths in the analytic sample. The CVD and cancer mortality rates were 5.9 and 4.0 per 1000 person-years, respectively. Obesity had a greater effect on CVD mortality than on overall mortality. The adjusted HRs for CVD mortality were $1.54(95 \%$ CI $1.16,2.04), 1.90$ (95\% CI 1.33, 2.74), 1.25 (95\% CI 0.70, 2.22) and 1.96 (95\% CI $1.36,2.83)$ comparing obese to non-obese participants per definitions by BMI, WC, WHtR and WHR, respectively (Fig. 3). No associations were found between obesity and cancer mortality (Fig. 3). 
(a) BMI

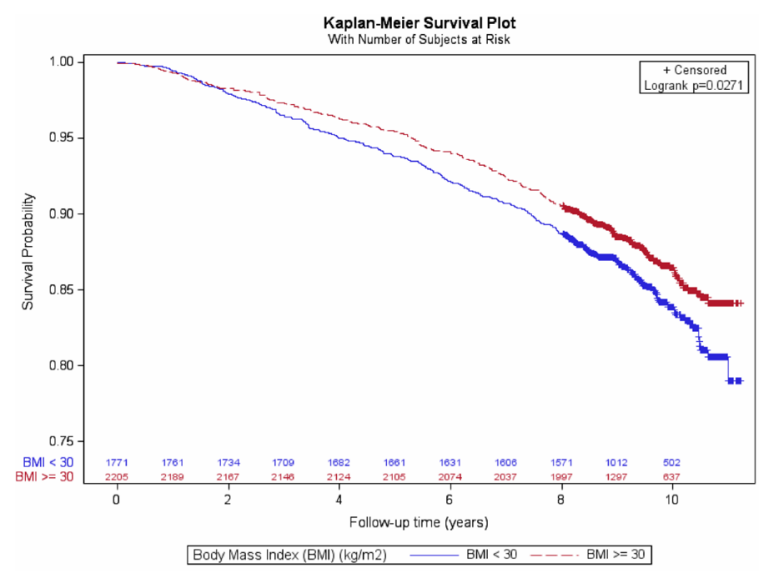

(c) Waist-to-Height Ratio

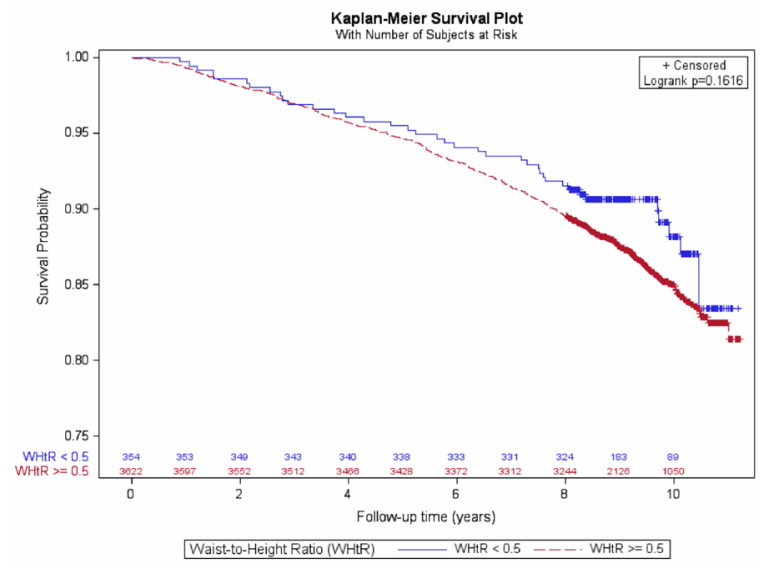

(b) Waist Circumference

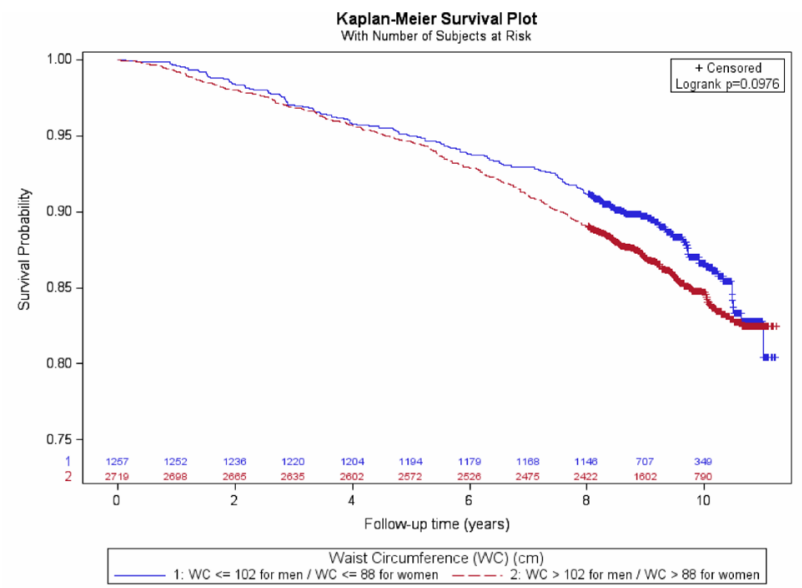

(d) Waist-to-Hip Ratio

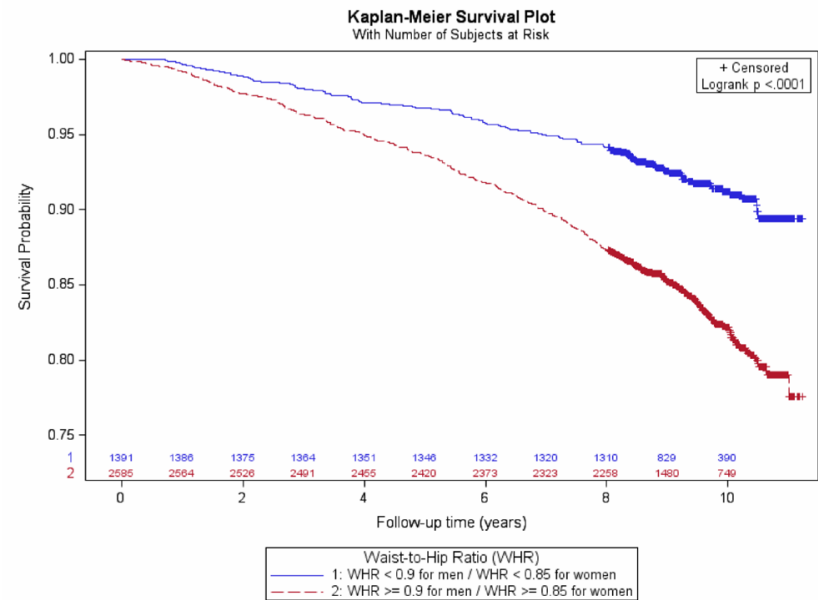

Fig. 1 Kaplan-Meier survival plot for overall mortality by obesity status (obese/non-obese)

\section{Discussion}

Our results show that obesity classified per WC and WHR, but not per BMI or WHtR, was associated with a significantly higher overall mortality after adjusting for age, sex and smoking status. We found a J-shaped relationship between BMI, WC, WHtR and overall mortality and a linear relationship between WHR and overall mortality. We found similar results for obesity classified per BMI, WC, WHR, and WHtR and CVD mortality. However, we found no associations between any of the obesity classifications and cancer mortality.

Our findings on BMI and overall mortality were consistent with findings reported in the literature. Overweight and mild obesity were associated with a lower overall mortality compared with normal BMI $(\mathrm{BMI}<25)$. This "J-shaped" association persisted even after excluding "early deaths," defined as participants who died within one year of enrollment and thus may have low BMI due to wasting.

We found that both WHR and WC adjusted for HC, but not WC alone, were linearly associated with overall mortality. This finding suggests that not only body fat but also the distribution of body fat is important in discriminating overall mortality risk. In a recent study, using computed tomography (CT)-measured body fat, including both visceral and subcutaneous fat area, Lee et al. [23] showed that only the visceral-to-subcutaneous fat area ratio (VSR) was independently associated with overall mortality in the fully adjusted model with age, sex, comorbidities and total fat mass. In another study using data from NHANES, Dong et al. [24] demonstrated that both amount of body fat and body fat 
Table 3 Overall mortality: obese vs. non-obese

\begin{tabular}{|c|c|c|c|c|}
\hline & \#event/\#obs & $\begin{array}{l}\text { Mortality }(95 \% \mathrm{Cl}) \\
(/ 1000 \text { Person-Years) }\end{array}$ & $\begin{array}{l}\text { HR }(95 \% \mathrm{Cl}) \\
\text { Unadjusted }\end{array}$ & $\begin{array}{l}\text { HR }(95 \% \mathrm{Cl}) \\
\text { Age-sex-smoking Adjusted }\end{array}$ \\
\hline Total & $551 / 3976$ & $15.4(14.3,16.5)$ & $\ldots$ & $\ldots$ \\
\hline \multicolumn{5}{|l|}{ BMI, $\mathrm{kg} / \mathrm{m}^{2}$} \\
\hline Non-obese & 269/1771 & $17.0(15.4,18.8)$ & 1.00 & 1.00 \\
\hline Obese & $282 / 2205$ & $14.1(12.8,15.6)$ & $0.83(0.70,0.98)$ & $1.14(0.96,1.35)$ \\
\hline \multicolumn{5}{|l|}{$\mathrm{WC}, \mathrm{cm}$} \\
\hline Non-obese & $156 / 1257$ & $13.8(12.0,15.8)$ & 1.00 & 1.00 \\
\hline Obese & $395 / 2719$ & $16.2(14.9,17.6)$ & $1.17(0.97,1.41)$ & $1.30(1.07,1.59)$ \\
\hline \multicolumn{5}{|l|}{ WHtR } \\
\hline Non-obese & $39 / 354$ & $12.3(9.4,16.1)$ & 1.00 & 1.00 \\
\hline Obese & $512 / 3622$ & $15.7(14.6,16.9)$ & $1.26(0.91,1.75)$ & $1.02(0.73,1.41)$ \\
\hline \multicolumn{5}{|l|}{ WHR } \\
\hline Non-obese & $114 / 1391$ & $9.0(7.7,10.4)$ & 1.00 & 1.00 \\
\hline Obese & $437 / 2585$ & $19.0(17.5,20.6)$ & $2.13(1.73,2.61)$ & $1.45(1.18,1.79)$ \\
\hline
\end{tabular}

$H R$ hazard ratio, $C l$ confidence interval, $B M I$ body mass index, WC waist circumference, $H C$ hip circumference, $W H t R$ waist-to-height ratio, $W H R$ waist-to-hip ratio

distribution (measured via WHR) were independently associated with overall mortality and the effect was sexdependent.

Some investigators have advocated that waist and hip circumferences be considered as separate variables and not as a ratio, considering two persons with the same WHR may have markedly different levels of waist circumferences [25]. We evaluated this approach in our study and found that the model with waist and hip circumferences as separate variables outperformed the model with WHR in predicting overall mortality. These results provide further support on the interplay of the visceral and gluteofemoral fat depots and body shape on overall mortality. Possible mechanisms of the protective effect of gluteofemoral fat include long-term fatty acid storage in this location thus reducing adverse effects associated with ectopic fat deposition [26]. Gluteofemoral fat has also been found to be associated with a beneficial adipokine profile, positively associated with leptin and adiponectin levels and negatively associated with inflammatory cytokines [26].

Our analyses exploring the effect of having multiple determinants of obesity on overall mortality showed that adding BMI or WC to WHR as determinants of obesity did not substantially improve the prediction of mortality risks. Participants deemed obese by WHR were $45 \%$ more likely to die compared to those deemed not obese. Whereas participants deemed obese by both BMI and WHR were $50 \%$ more likely to die compared to those deemed obese by neither; participants deemed obese by both WC and WHR were 54\% more likely to die compared to those deemed obese by neither.

Our findings of the effects of obesity on CVD mortality were similar to those on overall mortality and, as would be expected, obesity had a greater effect on CVD mortality than on overall mortality. Of note, although BMI $\geq 30 \mathrm{~kg} / \mathrm{m}^{2}$ (obese) was not associated with overall mortality after adjusting for age, sex and smoking compared to BMI $<30 \mathrm{~kg} / \mathrm{m}^{2}$, BMI-defined obesity was associated with a higher CVD mortality. This reaffirms the usefulness of this commonly used obesity indicator for monitoring trends of obesity and cardiovascular health.

We did not find an association between obesity and cancer mortality. It is possible that obesity-related metabolic dysregulations rather than merely obesity are required to show an association with cancer mortality [27, 28]. For example, in an analysis using data collected in the REasons for Geographic and Racial Differences in Stroke (REGA RDS) study, obesity was shown to be associated with a reduced risk for cancer mortality whereas glucose dysregulation and metabolic syndrome were associated with an increased risk for cancer mortality [28].

A limitation of the study is that because JHS is a sample of African Americans, we are unable to address directly whether or not race matters in body composition or outcome in this study. It has been observed that body compositions differ across race/ethnic groups. For a given $\mathrm{BMI}$, non-Hispanic (NH) blacks typically have the lowest percent fat mass (\%fat) followed by $\mathrm{NH}$ whites and Mexican Americans have the greatest \%fat [9]. $\mathrm{NH}$ blacks also have smaller waist circumferences than $\mathrm{NH}$ whites and Mexican Americans with similar BMI. Therefore, the findings of this study may not be generalizable to other race or ethnic groups.

\section{Conclusions}

In conclusion, we found that obesity classified by WC and WHR was significantly associated with an increased 
(a) BMI

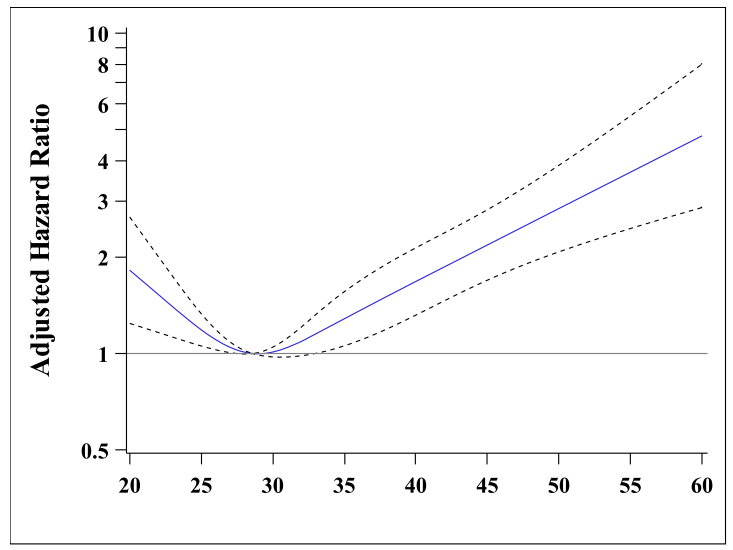

(c) Waist-to-Height Ratio (WHtR)

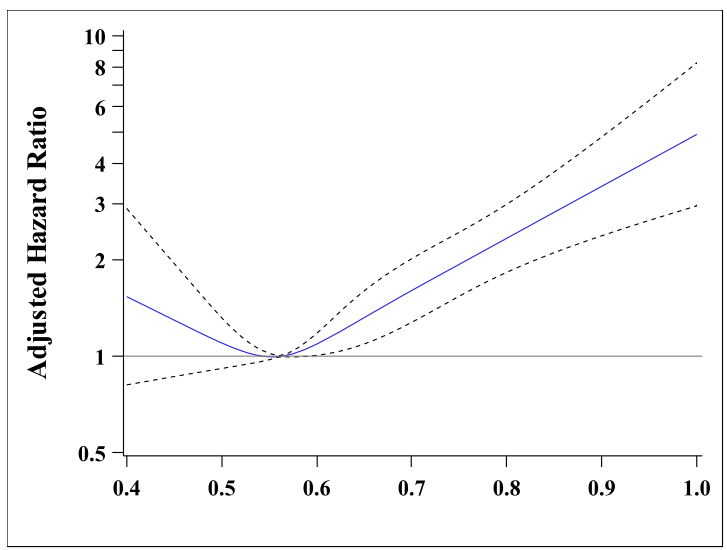

(b) Waist Circumference (WC)

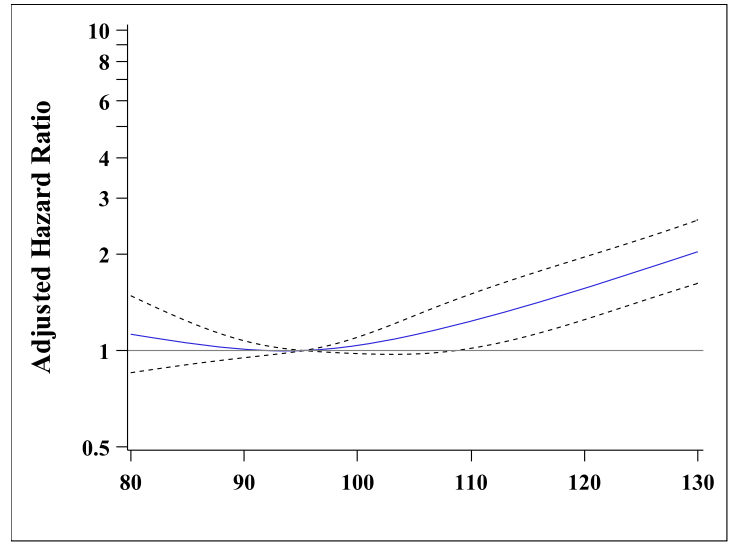

(d) Waist-to-Hip Ratio (WHR)

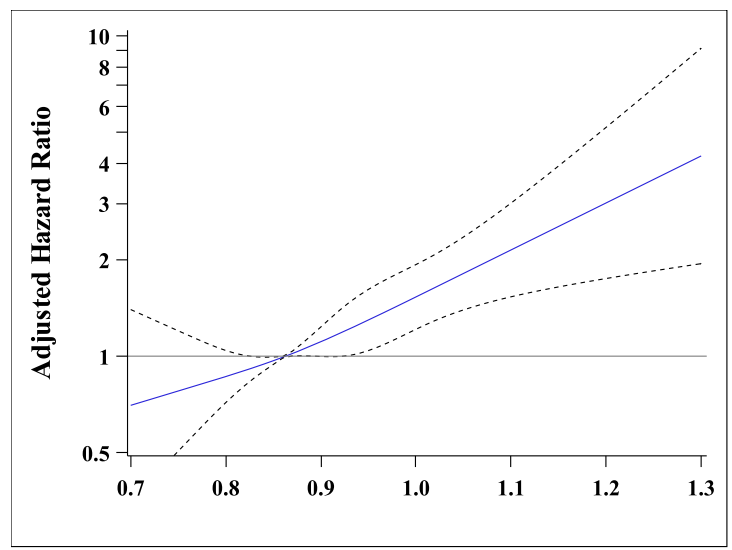

*Hazard ratios are adjusted for age, sex and smoking status.

Fig. 2 Adjusted hazard ratios* for overall mortality: analysis using restricted cubic splines

risk of overall and CVD mortality in this large cohort of African Americans. Additionally, obesity classified by BMI was significantly associated with an increased risk of CVD mortality. WHR was the only obesity measure that showed a monotonic increasing relationship with overall and CVD mortality. Further studies are warranted to determine the extent to which: (1) WC and/or WHR strata can be used as mortality risk indicators in research and population health policy for African Americans as is currently being done for $\mathrm{BMI}$; and (2) individuals with normal BMI but in high risk WC and/ or WHR strata might represent an appreciable target

Table 4 Overall mortality: hazard ratios by number of determinants of obesity

\begin{tabular}{llll}
\hline \# Determinants Present & N (\%) & $\begin{array}{l}\text { HR }(\mathbf{9 5} \% \mathbf{C l}) \\
\text { Age-sex-smoking Adjusted }\end{array}$ & Type 3 Test P-value Based on Wald statistics \\
\hline 0 & $658(16.6)$ & $1.00($ Ref $)$ & 0.0075 \\
1 & $673(16.9)$ & $1.19(0.86,1.65)$ & \\
2 & $1099(27.6)$ & $1.22(0.90,1.67)$ \\
3 & $1546(38.9)$ & $1.54(1.16,2.06)$ & \\
\hline
\end{tabular}


Table 5 Overall mortality: hazard ratios with different combinations of determinants of obesity

\begin{tabular}{|c|c|c|c|c|}
\hline Scenario & $\begin{array}{l}\text { \# Determinants } \\
\text { Present }\end{array}$ & $\mathrm{N}(\%)$ & $\begin{array}{l}\text { HR }(95 \% \mathrm{Cl}) \\
\text { Age-sex-smoking } \\
\text { Adjusted }\end{array}$ & $\begin{array}{l}\text { Type } 3 \text { Test P-value Based on Wald } \\
\text { statistics }\end{array}$ \\
\hline \multicolumn{5}{|l|}{ (a) $\mathrm{BMI}+\mathrm{WC}$} \\
\hline Non-obese & 0 & $1140(28.7)$ & 1.00 (Ref) & 0.0758 \\
\hline BMI obese or WC obese & 1 & $748(18.8)$ & $1.12(0.87,1.43)$ & \\
\hline BMI obese and WC obese & 2 & $2088(52.5)$ & $1.27(1.03,1.57)$ & \\
\hline \multicolumn{5}{|l|}{ (b) $\mathrm{BMI}+\mathrm{WHR}$} \\
\hline Non-obese & 0 & $785(19.7)$ & 1.00 (Ref) & 0.0062 \\
\hline BMI obese or WHR obese & 1 & $1592(40.0)$ & $1.24(0.95,1.62)$ & \\
\hline BMI obese and WHR obese & 2 & $1599(40.2)$ & $1.50(1.15,1.97)$ & \\
\hline \multicolumn{5}{|l|}{ (c) WC + WHR } \\
\hline Non-obese & 0 & $722(18.2)$ & 1.00 (Ref) & 0.0008 \\
\hline WC obese or WHR obese & 1 & $1204(30.3)$ & $1.16(0.86,1.57)$ & \\
\hline WC obese and WHR obese & 2 & $2050(51.6)$ & $1.54(1.17,2.04)$ & \\
\hline
\end{tabular}

$H R$ hazard ratio, $\mathrm{Cl}$ confidence interval, $B M I$ body mass index, WC waist circumference, $H C$ hip circumference, WHtR waist-to-height ratio, WHR waist-to-hip ratio

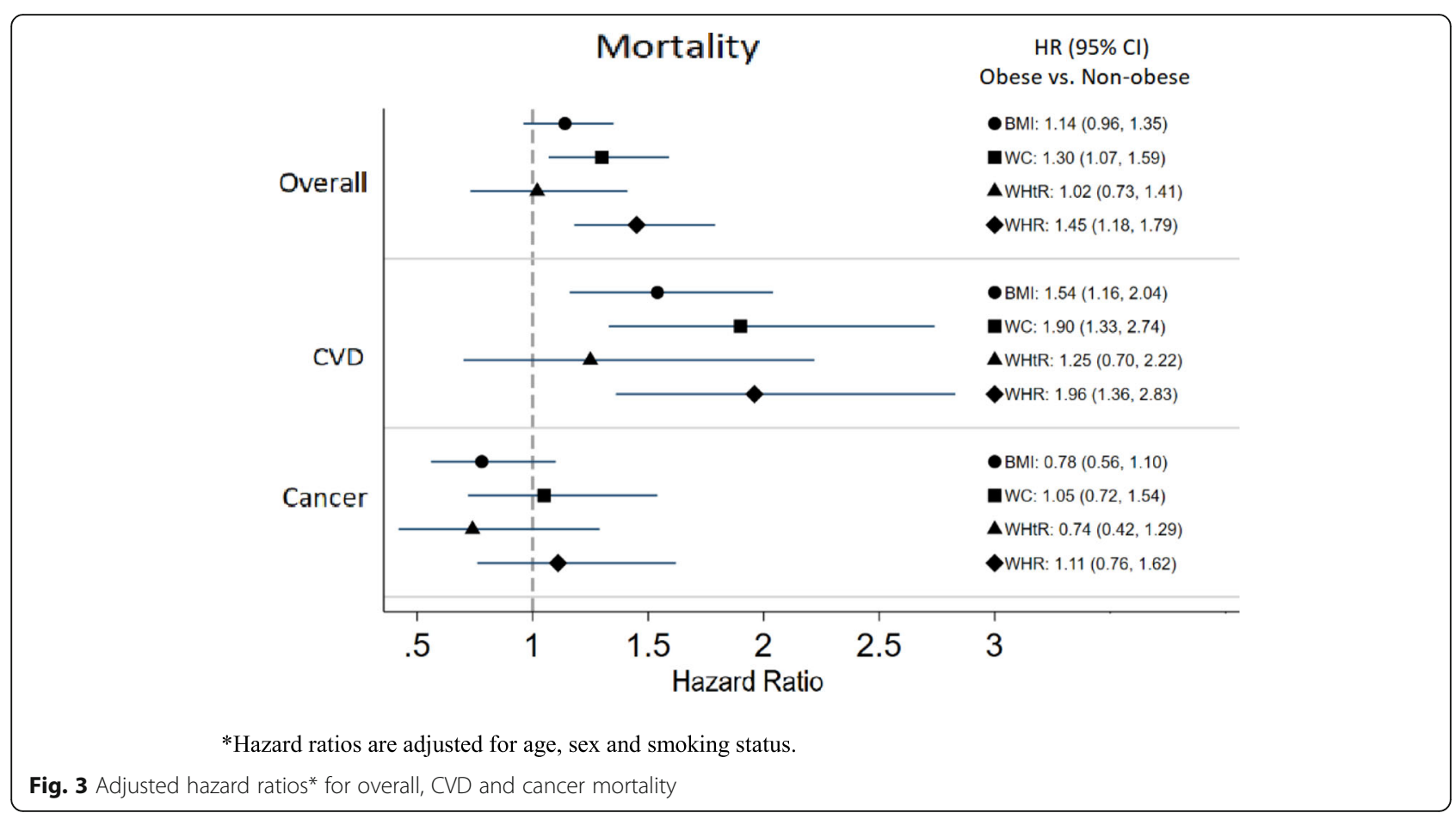


population subgroup for potential lifestyle modification. Our findings suggest that WHR, a measure that captures both central adiposity and body composition, may be an important anthropometric measure to collect to monitor obesity and obesity-related risks among African Americans. These findings should be verified in other ethnically diverse populations.

\begin{abstract}
Abbreviations
BioLINCC: Biologic Specimen and Data Repository Information Coordinating Center; BMI: Body mass index; cm: Centimeters; Cl: Confidence interval; CT: Computed tomography; CVD: Cardiovascular disease; HC: Hip circumference; HR: Hazard ratio; ICD: International classification of diseases: ICD-10: International Statistical Classification of Diseases and Related Health Problems, Tenth Revision; JHS: Jackson Heart Study; kg: Kilograms; kg/ $\mathrm{m}^{2}$ : Kilograms divided by meters squared; LRT: Likelihood ratio test; NCHS: National Center for Health Statistics; NH: Non-Hispanic; NHAN ES: National Health and Nutrition Examination Survey; NHLBI: National Heart, Lung, and Blood Institute; NIMHD: National Institute for Minority Health and Health Disparities; REGARDS: REasons for Geographic and Racial Differences in Stroke study; SD: Standard deviation; UK: United Kingdom; US: United States; VSR: Visceral-to-subcutaneous fat area ratio; WC: Waist circumference; WHR: Waist-to-hip ratio; WHtR: Waist-to-height ratio
\end{abstract}

\section{Acknowledgements}

The authors thank the participants and data collection staff of the Jackson Heart Study.

\section{Disclaimer}

The findings and conclusions in this report are those of the authors and do not necessarily represent the views of the National Heart, Lung, and Blood Institute; the National Institute for Minority Health and Health Disparities; the National Institutes of Health; or the U.S. Department of Health and Human Services.

\section{Authors' contributions}

YM-analysis and interpretation of data, drafting and final approval of the manuscript; YG-statistical expertise, critical review and final approval of the manuscript; PA-acquisition of data; critical review and final approval of the manuscript; AA-helped conduct the literature review, critical review and final approval of the manuscript; AC-conception and design of study, critical review and final approval of manuscript. All authors have read and approved the manuscript.

\section{Funding}

The Jackson Heart Study is supported by contracts from the National Heart, Lung, and Blood Institute (NHLBI) and the National Institute for Minority Health and Health Disparities (NIMHD) and is conducted in collaboration with Jackson State University (HHSN268201800013I), Tougaloo College (HHSN268201800014I), the Mississippi State Department of Health (HHSN268201800015I) and the University of Mississippi Medical Center (HHSN268201800010I, HHSN268201800011I and HHSN268201800012I). The funding agency did not play a role in the design of the study and collection, analysis, and interpretation of data and in writing the manuscript.

\section{Availability of data and materials}

As a National Heart, Lung, and Blood Institute (NHLBI)-funded study, the JHS follows the NHLBI's Policy for Data Sharing, which includes depositing the data into the NHLBI's Biologic Specimen and Data Repository Information Coordinating Center (BioLINCC) to make it publically available to other investigators. The link to the JHS dataset: https://biolincc.nhlbi.nih.gov/ studies/jhs/. Further download directions are provided on the website. NHLB further requires the JHS to maintain the accuracy of this dataset, so the JHS Coordinating Center sends modifications to BioLINCC for incorporation as appropriate. Privacy and access settings are controlled by BioLINCC, and the investigators have no influence on these settings.

\section{Ethics approval and consent to participate}

The study was approved by the Institutional Review Boards of the four participating institutions (Jackson State University, Tougaloo College, the Mississippi State Department of Health and the University of Mississippi Medical Center) and participants provided written informed consent.

\section{Consent for publication}

Not applicable.

\section{Competing interests}

None.

Received: 27 February 2020 Accepted: 9 December 2020

Published online: 06 January 2021

References

1. Flegal KM, Kit BK, Orpana H, Graubard BI. Association of all-cause mortality with overweight and obesity using standard body mass index categories: a systematic review and meta-analysis. JAMA. 2013;309:71-82.

2. Donini LM, Savina C, Gennaro E, De Felice MR, Rosano A, Pandolfo MM, Del Balzo V, Cannella C, Ritz P, Chumlea WMC. A systematic review of the literature concerning the relationship between obesity and mortality in the elderly. J Nutr Health Aging. 2012;16:89-98.

3. Oga EA, Eseyin OR. The obesity paradox and heart failure: a systematic review of a decade of evidence. J Obesity. 2016. Artical ID 904024.

4. Schmidt DS, Salahudeen AK. Cardiovascular and survival paradoxes in dialysis patients: obesity-survival paradox-still a controversy? Semin Dial. 2007;20:486-92.

5. Cao C, Wang R, Wang J, Bunjhoo H, Xu Y, Xiong W, Simpson C. Body mass index and mortality in chronic obstructive pulmonary disease: a metaanalysis. PLoS One. 2012;7:e43892.

6. Zheng $\mathrm{H}$, Dirlam J. The body mass index-mortality link across the life course: two selection biases and their effects. PLOS ONE. 2016. https://doi.org/10. 1371/journal.pone.0148178.

7. Lee DH, Keum N, Hu FB, Orav EJ, Rimm EB, Willet WC Giovannucci. Predicted lean body mass, fat mass, and all cause and cause specific mortality in men: prospective US cohort study. BMJ. 2018;362:k2575.

8. Atkins JL, Whincup PH, Morris RW, Lennon LT, Papacosta O, Wannamethee SG. Sarcopenic obsesity and risk of cardiovascular disease and mortality: a population-based cohort study of older men. J Am Geriatr Soc. 2014;62: 253-60.

9. Heymsfield SB, Peterson CM, Thomas DM, Heo M, Schuna JM Jr. Why are there race/ethnic differences in adult body mass index-adiposity relationships? A quantitative critical review. Obes Rev. 2016:17:262-75.

10. Lee CMY, Huxley RR, Wildman RP, Woodward M. Indices of abdominal obesity are better discriminators of cardiovascular risk factors than BMI: a meta-analysis. J Clin Epidemiol. 2008;61:646-53.

11. Bell RA, Chen H, Saldana S, Bertoni AG, Effoe VS, Hairston KG, Kalyani RR, Norwood AF. Comparison of measures of adiposity and cardiovascular disease risk factors among African American adults: the Jackson Heart Stuty. J Racial Ethn Health Disparities. 2018;5:1230-7.

12. Lauby-Sevretan B, Scoccianti C, Loomis D, Grosse Y, Bianchini F, Straif K, for the International Agency for Research on Cancer Handbook Working Group. Body fatness and Cancer - viewpoint of the IARC working group. NEJM. 2016:375:794-8.

13. Taylor HA. The Jackson heart study: an overview. Ethnicity Dis. 2005;15(4 Suppl 6):1-3.

14. Carpenter MA, Crow R, Steffes M, Rock W, Heilbraun J, Evans G, Skelton T, Jensen R, Sarpong D. Laboratory, reading center, and coordinating center data management methods in the Jackson heart study. Am J Med Sci. 2004; 328:131-44.

15. Keys A, Karvonen N, Kimura N, Taylor HL. Indices of relative weight and obesity. J Chronic Dis. 1972;25:329-43.

16. World Health Organization. International statistical classification of diseases and related health problems, tenth revision (ICD-10). 2008 ed. Geneva: World Health Organization; 2009.

17. Heron M. Deaths: Leading causes for 2012. National vital statistics reports; vol 64 no 10. Hyattsville, MD: National Center for Health Statistics; 2015.

18. National Institutes of Health. Clinical guidelines on identification, evaluation and treatment of overweight and obesity in adults. Obes Res. 1998:6(Suppl 2):51S-209S Erratum in Obes Res. 1998;6:464. 
19. World Health Organization. Waist circumference and waist-hip ratio: report of a WHO expert consultation, Geneva, 8-11 December 2008. World Health Organization; 2011

20. Ashwell M, Gunn P, Gibson S. Waist-to-height ratio is a better screening tool than waist circumference and BMI for adult cardiometabolic risk factors: systematic review and meta-analysis. Obes Rev. 2012;13:275-86.

21. Harrell FE. Regression modeling strategies with applications to linear models, logistic and ordinal regression and survival analysis, $2^{\text {nd }}$ ed. Cham: Springer-Verlag; 2015. ISBN 978-3-319-19424-0.

22. Fine JP, Gray RJ. A proportional hazards model for the subdistribution of a competing risk. J Am Stat Assoc. 1999:94:496-509.

23. Lee SW, Son JY, Kim JM, Hwang S, Han JS, Heo NJ. Body fat distribution is more predictive of all-cause mortality than overall adiposity. Diabetes Obes Metab. 2018;20:141-7.

24. Dong B, Peng Y, Wang Z, Adegbija O, Hu J, Ma J, Ma YH. Joint association between body fat and its distribtuion with all-cause mortality: a data linkage cohort study based on NHANES (1988-2011). PLoS One. 2018;13(2): e0193368

25. Cameron AJ, Magliano DJ, Soderberg S. A systematic review of the impact of including both waist and hip waist circumference in risk models for cardiovascular diseases, diabetes and mortality. Obes Rev. 2013;14:86-94.

26. Manolopoulos KN, Karpe F, Frayn KN. Gluteofemoral body fat as a determinant of metabolic health. Int J Obes. 2010;34:949-59.

27. Gallagher EJ, LeRoith D. Obesity and diabetes: the increased risk of cancer and cancer-related mortality. Physiol Rev. 2015;95:727-48.

28. Akinyemiju T, Moore JX, Judd S, Lakoski S, Goodman M, Safford MM, Pisu M. Metabolic dysregulation and cancer mortality in a national cohort of blacks and whites. BMC Cancer. 2017;17:856.

\section{Publisher's Note}

Springer Nature remains neutral with regard to jurisdictional claims in published maps and institutional affiliations.

Ready to submit your research? Choose BMC and benefit from:

- fast, convenient online submission

- thorough peer review by experienced researchers in your field

- rapid publication on acceptance

- support for research data, including large and complex data types

- gold Open Access which fosters wider collaboration and increased citations

- maximum visibility for your research: over $100 \mathrm{M}$ website views per year

At $\mathrm{BMC}$, research is always in progress.

Learn more biomedcentral.com/submissions 